\title{
Lymphoma associated hemophagocytic syndrome: A single-center retrospective study
}

\author{
YU CHANG $^{1}$, MENG CUI $^{2}$, XIAORUI FU ${ }^{1}$, LIJUAN HAN ${ }^{1}$, LEI ZHANG ${ }^{1}$, LING LI $^{1}$, \\ XIN LI $^{1}$, ZHENCHANG SUN $^{1}$, JINGJING WU ${ }^{1}$, XUDONG ZHANG ${ }^{1}$, ZHAOMING LI $^{1}$, \\ FEIFEI NAN ${ }^{1}$, JIAQIN YAN $^{1}$, GUANGYAO SHENG $^{3}$ and MINGZHI ZHANG ${ }^{1}$ \\ ${ }^{1}$ Department of Oncology, The First Affiliated Hospital of Zhengzhou University; \\ ${ }^{2}$ Department of Head and Neck and Thyroid, Henan Cancer Hospital Affiliated to Zhengzhou University; \\ ${ }^{3}$ Department of Pediatrics, The First Affiliated Hospital of Zhengzhou University, Zhengzhou, Henan 450052, P.R. China
}

Received October 6, 2016; Accepted April 3, 2018

DOI: $10.3892 / \mathrm{ol} .2018 .8783$

\begin{abstract}
To improve the understanding of lymphoma associated hemophagocytic syndrome (LAHS) and find an effective treatment for this fatal disease, 57 patients with LAHS were retrospectively reviewed. The most common histopathological type was extranodal natural killer (NK)/T-cell lymphoma, nasal type (ENKL) (45.61\%). Patients with B-cell LAHS were significantly older $(\mathrm{P}<0.001)$, and exhibited a higher triglyceride level $(\mathrm{P}=0.012)$, lower serum ferritin level $(\mathrm{P}=0.014)$ and lower plasma Epstein-Barr virus DNA $(\mathrm{P}<0.001)$ compared with patients with T/NK-cell LAHS. The median survival time of all patients was 43 days, and patients with B-cell $(n=14)$ and T/NK-cell $(n=43)$ LAHS had a median survival time of 55 and 40 days, respectively $(\mathrm{P}=0.797)$. Compared with patients who were treated based on HLH-2004 protocols combined with multidrug chemotherapy, those without chemotherapy had a reduced prognosis $(\mathrm{P}=0.002)$. The patients that underwent hematopoietic stem cell transplantation (HSCT) following chemotherapy had a significantly improved overall survival (OS) compared with patients that did not undergo HSCT $(\mathrm{P}=0.001)$. Patients with B-cell LAHS treated with rituximab $(\mathrm{P}=0.015)$ and patients with ENKL treated with L-asparaginase/pegaspargase (L-asp/peg) $(\mathrm{P}=0.009)$ had an improved prognosis compared with patients not treated with these drugs. In the T/NK-cell LAHS group, patients treated with chemotherapy containing gemcitabine did not exhibit
\end{abstract}

Correspondence to: Professor Mingzhi Zhang, Department of Oncology, The First Affiliated Hospital of Zhengzhou University, 1 Jianshe Road, Zhengzhou, Henan 450052, P.R. China

E-mail: mingzhi_zhang1@163.com

Professor Guangyao Sheng, Department of Pediatrics, The First Affiliated Hospital of Zhengzhou University, 1 Jianshe Road, Zhengzhou, Henan 450052, P.R. China

E-mail: shenggy2959@126.com

Key words: hemophagocytic syndrome, lymphoma, clinical features, early diagnosis, prognosis an improved OS compared with those not treated with gemcitabine $(\mathrm{P}=0.326)$. Furthermore, multivariate analysis demonstrated that long diagnosis time and poor performance status were independent prognosis factors for all patients with LAHS. The present study indicated that survival time does not differ between patients with B-cell LAHS and patients with T/NK-cell LAHS. Early diagnosis and appropriate immunochemotherapy plus HSCT are essential to achieve improved outcomes. The outcome of patients with B-cell LAHS may be significantly improved following treatment with rituximab. L-asp/peg-containing regimens are promising treatments for patients with NK/T-cell LAHS.

\section{Introduction}

Hemophagocytic syndrome (HPS) or hemophagocytic lymphohistiocytosis (HLH), which was first reported as virus-associated HPS by Risdall et al (1), represents an uncontrolled immune response triggered by various stimuli. The excessive activation of lymphocytes and macrophages produces a high level of inflammatory cytokines, including interferon (IFN)- $\gamma$, interleukin (IL)-12, IL-18 and tumor necrosis factor (TNF)- $\alpha$ (2). The cytokine storm and infiltration of activated macrophages are responsible for features, including persistent fever, hepatosplenomegaly, pancytopenia and hemophagocytosis in bone marrow, liver and other organs (2-4). HPS is classified into primary and secondary forms. Primary HPS generally occurs in infants or young children with a clear genetic or familial inheritance (2). Due to a variety of underlying conditions, secondary HPS development may be triggered by infections, autoimmune disorders, malignancies and immunosuppression $(3,5)$.

Lymphoma is the most common underlying condition of malignancy-associated HPS. HPS may occur as an initial presentation of lymphoma, as well as a complication at the relapsed or advanced stage of lymphoma (6). It was reported that the most common type of lymphoma-associated HPS (LAHS) was T/natural killer (NK)-cell lymphoma and there were fewer cases derived from B-cell lymphomas $(7,8)$. Currently, LAHS is considered to be life-threatening. Few systematic reports are available on LAHS (9). The median survival time for patients 
with NK/T-cell and other types of T-cell lymphoma is 28 and 33 days, respectively (6). Han et al (8) reviewed 29 patients with LAHS and determined that the median survival time was only 36 days. Furthermore, there are ongoing discussions in various aspects of LAHS, including specific indicators for early diagnosis, therapeutic regimens and hematopoietic stem cell transplantation (HSCT) (9-11). Therefore, in the present study, the clinical features, treatment and prognosis factors of 57 patients with LAHS were analyzed. To the best of our knowledge, the present study used the largest cohort of patients with LAHS. Furthermore, the differences between B-cell and T/NK-cell LAHS were discussed in order to improve the understanding of LAHS and attempt to find an appropriate treatment for this disease.

\section{Patients and methods}

Patient selection. A total of 57 patients diagnosed with LAHS (34 males and 23 females) were selected from the First Affiliated Hospital of Zhengzhou University (Zhengzhou, China), who enrolled from December 2008 to March 2016. The median age was 36 years old with an age range of 4-76 years old. All patients underwent laboratory tests, including blood routine test, liver and kidney function, lactate dehydrogenase, $\beta 2$-microglobulin, serum ferritin, coagulation function and polymerase chain reaction tests for Epstein-Barr virus (EBV)-DNA. Bone marrow smears and biopsies were assessed.

Diagnosis of lymphoma was confirmed according to the World Health Organization classification of hematopoietic and lymphoid tumors in 2008 (12). Diagnosis of HPS was based on the Histiocyte Society HLH-2004 pediatric diagnostic criteria (13). NK cell activity and soluble CD25 levels were not evaluated. The stage of lymphoma was evaluated by Ann Arbor staging system (14) through computed tomography (CT) scans or positron emission tomography (PET)/CT. Performance status was assessed based on the Eastern Cooperative Oncology Group (ECOG) scale (15). Immuno-chemotherapy was based on HLH-2004 protocols (13). Etoposide-based regimens were followed, including dexamethasone, cyclosporine A (CSA), intravenous immunoglobulins and intrathecal therapy. The treatment response was assessed according to Cheson et al (16).

Statistical analysis. The data was presented as the mean \pm standard deviation. The sample normality detection was assessed using a Shapiro-Wilk test. Clinical and laboratory data of patients were assessed using Pearson's $\chi^{2}$ test, Fisher's exact test, Kruskal-Wallis test, independent-samples Student's t-test or Mann Whitney U test. Overall survival (OS) time, measured as the period from diagnosis to mortality or the last follow-up, was estimated by the Kaplan-Meier method. Survival rates were compared by the log-rank test. Univariate analysis using Cox proportional hazards model was used to calculate hazard ratios of prognostic factors for patients with LAHS. Multivariate analysis using Cox proportional hazards model was used to identify the potential independent effects of those factors. $\mathrm{P}<0.05$ was considered to indicate a statistically significant difference. The software package SPSS 21.0 (IBM Corp., Armonk, NY, USA) was used for statistical analysis.

\section{Results}

Patient characteristics. Patient characteristics are summarized in Table I. There were 43 patients diagnosed with T/NK-cell lymphoma, accounting for $75.44 \%$ of all patients with LAHS. The most frequent histopathological type was extranodal natural killer/T-cell lymphoma, nasal type (ENKL) (45.61\%). The other types included diffuse large B-cell lymphoma (24.56\%), anaplastic large cell lymphoma (10.53\%), peripheral T cell lymphoma, not otherwise specified (8.77\%), progressive NK/T-cell leukemia (PNKTL) (5.26\%), subcutaneous panniculitis-like T-cell lymphoma (3.51\%) and hepatosplenic T-cell lymphoma (1.75\%). The majority of patients $(92.98 \%)$ were classified into Ann Arbor III-IV stage. Among all patients, 21 had a history of lymphoma (had been previously diagnosed with lymphoma) and were diagnosed with HPS at the advanced Ann Arbor stage of lymphoma. The most frequent symptom was fever (100\%), followed by splenomegaly (92.89\%), multicavity effusion $(56.14 \%)$, hepatomegaly (43.86\%), jaundice $(31.58 \%)$ and edema (31.58\%). A total of 56 patients exhibited thrombocytopenia $(98.25 \%), 48$ patients $(84.21 \%)$ had a high level of aspartate aminotransferase, 47 patients $(82.46 \%)$ had an elevated level of serum ferritin and 39 patients had hemophagocytosis in the bone marrow (68.42\%).

The comparison of clinical features and laboratory data between patients with B-cell and T/NK-cell LAHS are listed in Tables II and III. Compared with patients with T/NK-cell LAHS, patients with B-cell LAHS were older $(\mathrm{P}<0.001)$, had a higher level of triglycerides $(\mathrm{P}=0.012)$, and a lower level of serum ferritin $(\mathrm{P}=0.014)$ and the number of copies of $\mathrm{EBV}$ DNA $(\mathrm{P}<0.001)$. The differences in the remaining features were not statistically significant.

Treatment and survival. Following a median follow-up of 33 days (range, 5-1,133 days), 52/57 patients (91.23\%) had succumbed. The median survival time of all patients was 43 days (range, 5-1,133 days). Survival curves are depicted in Fig. 1. The median survival time of patients with B-cell LAHS and T/NK-cell LAHS was 55 (range, 11-1,133 days) days and 40 days (range, 5-809 days), respectively $(\mathrm{P}=0.797)$. The 0.5 , 1 and 2-year OS rates for patients with B-cell LAHS were $16.0,16.0$ and $8.0 \%$, respectively. The rates for OS for patients with T/NK-cell LAHS were 26.0, 17.0 and 13.0\%, respectively. Compared with 41 patients who were treated with the HLH-2004 regimen combined with multidrug chemotherapy (median survival time, 55 days), those who only received the HLH-2004 regimen (and did not receive chemotherapy for lymphoma) had a significantly reduced prognosis (median survival time, 25 days) ( $\mathrm{P}=0.002$; Fig. 2A). Of the 57 patients, five underwent autologous or allogeneic HSCT following chemotherapy and had a significantly improved OS (median survival time, 1,110 days) compared with the 52 remaining patients without HSCT (median survival time, 36 days) $(\mathrm{P}=0.001$; Fig. 2B).

Of 14 patients with B-cell LAHS, five were treated with CSA or dexamethasone and four patients faced rapid disease progression in a short time. A total of 3 patients with B-cell LAHS received chemotherapy plus rituximab, and two patients exhibited complete remission (CR). The survival time of the 3 patients who received chemotherapy plus rituximab 
Table I. Characteristics of all patients with lymphoma associated hemophagocytic syndrome.

\begin{tabular}{|c|c|}
\hline Characteristics & Patients, n (\% \\
\hline \multicolumn{2}{|l|}{ Sex (male) } \\
\hline Male & $34(59.65)$ \\
\hline Female & $23(40.35)$ \\
\hline B-cell lymphoma & $14(24.56)$ \\
\hline DLBCL & $14(24.56)$ \\
\hline T/NK/-cell lymphoma & $43(75.44)$ \\
\hline ENKL & $26(45.61)$ \\
\hline PNKL & $3(5.26)$ \\
\hline PTCL, NOS & $5(8.77)$ \\
\hline ALCL & $6(10.53)$ \\
\hline SPTL & $2(3.51)$ \\
\hline HSTL & $1(1.75)$ \\
\hline Ann Arbor Stage I-II & $4(7.02)$ \\
\hline Ann Arbor Stage III-IV & $53(92.98)$ \\
\hline Previous lymphoma history & $21(36.84)$ \\
\hline \multicolumn{2}{|l|}{ Symptoms and signs } \\
\hline Fever & $57(100)$ \\
\hline Splenomegaly & $53(92.89)$ \\
\hline Hepatomegaly & $25(43.86)$ \\
\hline Multicavity effusion & $32(56.14)$ \\
\hline Jaundice & $18(31.58)$ \\
\hline Edema & $18(31.58)$ \\
\hline \multicolumn{2}{|l|}{ Laboratory data } \\
\hline $\mathrm{ANC}<1.5 \times 10^{9} / 1$ & $41(71.93)$ \\
\hline $\mathrm{Hb}<90 \mathrm{~g} / \mathrm{l}$ & $36(63.16)$ \\
\hline PLT $<100 \times 10^{9} / 1$ & $56(98.25)$ \\
\hline ALT >40 U/1 & $46(80.70)$ \\
\hline $\mathrm{AST}>40 \mathrm{U} / 1$ & $48(84.21)$ \\
\hline ALB <30 g/l & $38(66.67)$ \\
\hline $\mathrm{TBIL}>25 \mu \mathrm{mol} / 1$ & $23(40.35)$ \\
\hline $\mathrm{LDH}>500 \mathrm{U} / 1$ & $40(70.18)$ \\
\hline FIB $<1.5 \mathrm{~g} / 1$ & $40(70.18)$ \\
\hline $\mathrm{TG}>3.0 \mathrm{mmol} / \mathrm{l}$ & $22(38.60)$ \\
\hline Ferritin $>1,000 \mu \mathrm{g} / 1$ & $47(82.46)$ \\
\hline EBV DNA copies $>10^{2}$ & $39(68.42)$ \\
\hline BM hemophagocytosis & $39(68.42)$ \\
\hline
\end{tabular}

DLBCL, diffuse large B cell lymphoma; NK, natural killer; ENKL, extranodal NK/T cell lymphoma, nasal type; PNKTL, progressive NK/T-cell leukemia; PTCL, NOS peripheral T-cell lymphoma, not otherwise specified; ALCL, systemic anaplastic large cell lymphoma; SPTL, subcutaneous panniculitis like T-cell lymphoma; HSTL, hepatosplenic T-cell lymphoma; ANC, absolute neutrophil count; $\mathrm{Hb}$, hemoglobin; PLT, platelets; ALT, alanine aminotransferase; AST, aspartate aminotransferase; ALB, albumin; TBIL, total bilirubin; LDH, lactate dehydrogenase; FIB, fibrinogen; TG, triglyceride; EBV, Epstein-Barr virus; BM, bone marrow.

(median, 645 days) was significantly longer compared with 6 patients who did not receive rituximab (median, 53 days) $(\mathrm{P}=0.015$; Fig. 3A). For patients with T/NK-cell LAHS,
17 patients underwent chemotherapy with gemcitabine, and they did not exhibit a significantly improved OS (median, 56 days), compared with 15 patients not treated with gemcitabine (median, 27 days) $(\mathrm{P}=0.326$; Fig. 3B). For patients with ENKL, 13 patients received chemotherapy regimens with L-asparaginase (L-asp) or pegaspargase (peg), and they had an improved prognosis (median survival time, 56 days) compared with 7 patients not treated with these drugs (median survival time, 20 days) ( $\mathrm{P}=0.009$; Fig. 3C).

Univariate and multivariate analysis for prognostic factors. The results of the univariate analysis of patients with LAHS are presented in Table IV. Among the patients with B-cell LAHS, it was determined that OS was significantly associated with serum ferritin level $(\mathrm{P}=0.036)$. However, the following factors predicted poor OS for patients with T/NK-cell LAHS and all patients with LAHS: Long diagnosis time $(\mathrm{P}<0.001$ for both); high ECOG scores ( $\mathrm{P}=0.024$ and $\mathrm{P}=0.005$, respectively); low hemoglobin ( $\mathrm{P}=0.023$ and $\mathrm{P}=0.005$, respectively); and high EBV DNA copies $(\mathrm{P}=0.011$ and $\mathrm{P}=0.004$, respectively). Furthermore, low level of fibrinogen was also a negative prognostic factor $(\mathrm{P}=0.036)$ for all patients with LAHS. Other baseline characteristics were not significantly associated with prognosis.

As presented in Table V, multivariate analysis was performed using the Cox proportional hazards model to assess the potential independent prognostic factors. Results demonstrated that diagnosis time $(\mathrm{P}=0.021)$ and ECOG scores $(\mathrm{P}=0.022)$ were independent predictors of all patients with LAHS. Furthermore, diagnosis time $(\mathrm{P}=0.003)$ was an independent predictor of patients with T/NK-cell LAHS. The median survival time of patients with long diagnosis time (>20 days) and high ECOG score (3-5 scores) was 25.3 and 30.9 days, respectively. However, the median survival time of patients with a short diagnostic time ( $\leq 20$ days) and low ECOG score (0-2 scores) was 85.0 and 383.8 days, respectively. For patients with T/NK-cell, the median survival time of patients with long and short diagnosis time were 23.7 and 213.1 days, respectively.

\section{Discussion}

To the best of our knowledge, this is one of the largest cohort of patients with LAHS in a study. The present study demonstrated that LAHS, a subtype of secondary HPS, has specific clinical features, prognostic factors and outcomes. A total of 57 patients with LAHS were retrospectively reviewed in the present study. A total of 43 patients were diagnosed with T/NK-cell LAHS. Patients with ENKL and PNKTL accounted for half of all patients with LAHS. Although a number of reports stated that there were an increasing number of B-LAHS cases $(17,18)$, the majority of reported cases of LAHS remained as T/NK-cell lymphoma $(8,9,19)$, which was consistent with the present study.

In the present study, patients with B-cell LAHS and T/NK-cell LAHS shared similar clinical features and laboratory data; however, patients with B-cell LAHS were older, which was similar to the previous studies by Han et al (8) and Sano et al (9). Patients with T/NK-cell LAHS also presented a higher level of serum ferritin compared with patients with 
Table II. Clinical features of patients with B-cell LAHS and T/NK-cell LAHS.

\begin{tabular}{|c|c|c|c|}
\hline Patients' Characteristics & B-cell lymphoma $(n=14)$ & T/NK-cell lymphoma $(n=43)$ & P-value \\
\hline Sex & & & $0.397^{\mathrm{a}}$ \\
\hline Male & 7 & 27 & \\
\hline Female & 7 & 16 & \\
\hline Age (years); mean $\pm \mathrm{SE}$ & $51.1 \pm 4.0$ & $33.1 \pm 2.2$ & $<0.001^{\mathrm{c}}$ \\
\hline IPI score & & & $0.720^{\mathrm{d}}$ \\
\hline $0-1$ & 0 & 2 & \\
\hline $2-3$ & 8 & 19 & \\
\hline $4-5$ & 6 & 22 & \\
\hline ECOG & & & $0.822^{\mathrm{a}}$ \\
\hline $0-2$ & 4 & 9 & \\
\hline $3-5$ & 10 & 34 & \\
\hline Splenomegaly & & & $1.000^{\mathrm{b}}$ \\
\hline Yes & 13 & 41 & \\
\hline No & 1 & 2 & \\
\hline Hepatomegaly & & & $0.479^{\mathrm{a}}$ \\
\hline Yes & 5 & 20 & \\
\hline No & 9 & 23 & \\
\hline Multicavity effusion & & & $0.931^{\mathrm{a}}$ \\
\hline Yes & 8 & 24 & \\
\hline No & 6 & 19 & \\
\hline Jaundice & & & $0.958^{\mathrm{a}}$ \\
\hline Yes & 5 & 13 & \\
\hline No & 9 & 30 & \\
\hline Edema & & & $0.958^{\mathrm{a}}$ \\
\hline Yes & 5 & 13 & \\
\hline No & 9 & 30 & \\
\hline Previous lymphoma history & & & $0.169^{\mathrm{a}}$ \\
\hline Yes & 3 & 18 & \\
\hline No & 11 & 25 & \\
\hline Diagnosis time (days); median (range) & $22.5(6.0-42.0)$ & $20.0(5.0-90.0)$ & $0.993^{\mathrm{e}}$ \\
\hline
\end{tabular}

LAHS, lymphoma associated hemophagocytic syndrome; SE, standard error; IPI, International Prognostic Index; ECOG, Eastern Cooperative

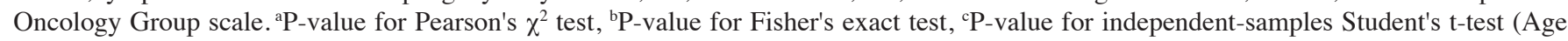
observes the normal distribution by means of Shapiro-Wilk test), ${ }^{\mathrm{d}} \mathrm{P}$-value for Kruskal-Wallis test, ${ }^{\mathrm{e}} \mathrm{P}$-value for Mann Whitney U test.

B-cell LAHS. In a study conducted by Yu et al (18), serum ferritin level was significantly higher in patients with T-cell LAHS, which was consistent with the present result. They also considered that a higher ferritin level may be associated with reduced survival outcome in patients with T-cell LAHS, as hyperferritinemia may indicate elevated cytokine activation and result in activating hepatic proinflammatory mediators through the nuclear factor- $\kappa \mathrm{B}$ signaling pathway (18). Allen et al (20) reported that a ferritin level $>10,000 \mu \mathrm{g} / \mathrm{l}$ was $90 \%$ sensitive and $96 \%$ specific for HPS; however, a high level of ferritin alone is just indicative, and the diagnosis of HPS may not be confirmed.

In the present study, plasma EBV DNA was determined to be higher in patients with T/NK-cell LAHS compared with patients with B-cell LAHS, whereas Yu et al (18) indicated that there was no significant difference between patients with T-cell and B-cell lymphoma in the presence of an EBV infection. Opposing results may be due to numerous reasons. Firstly, the constituent ratio of the underlying disease was different. In the present study a total of $2 / 3$ of the T/NK-cell lymphoma accounted for ENKL, whereas ENKL accounted for $<6 \%$ according to $\mathrm{Yu}$ et al (18). Furthermore, in the study by $\mathrm{Yu}$ et $a l$, patients were only checked if they were EBV-positive, whereas in the present study overall plasma EBV DNA copies were detected. EBV serves an important role in T/NK-cell lymphoma as well as EBV-associated HPS, and it may cause oncogenesis or occur in tumor-associated lymphocytes as a function of immune dysregulation (21). A number of previous studies have confirmed that plasma EBV-DNA was a prognostic marker for ENKL $(22,23)$. EBV-infected $\mathrm{T}$ cells selectively upregulate $\mathrm{TNF}-\alpha$ expression, which may activate macrophages in combination with IFN- $\gamma$ and other 
Table III. Laboratory data of patients with B-cell LAHS and T/NK-cell LAHS.

\begin{tabular}{|c|c|c|c|}
\hline Features median (range) & B-cell lymphoma $(n=14)$ & T/NK-cell lymphoma $(n=43)$ & P-value \\
\hline ANC (x10 $/ 1)$ & $1.3(0.0-3.0)$ & $0.8(0.0-5.3)$ & $0.082^{\mathrm{a}}$ \\
\hline $\mathrm{Hb}(\mathrm{g} / \mathrm{l}) ;$ mean $\pm \mathrm{SE}$ & $84.5 \pm 6.1$ & $83.4 \pm 3.0$ & $0.858^{\mathrm{b}}$ \\
\hline $\operatorname{PLT}\left(x 10^{9} / 1\right)$ & $26.5(7.0-96.0)$ & $22.0(2.0-129.0)$ & $0.475^{\mathrm{a}}$ \\
\hline \multicolumn{4}{|l|}{ Liver function } \\
\hline ALT (U/l) & $81.5(12.0-755.0)$ & $108.0(5.0-578.0)$ & $0.404^{\mathrm{a}}$ \\
\hline AST (U/l) & $140.0(15.0-1227.0)$ & $160.0(6.0-1294.0)$ & $0.904^{\mathrm{a}}$ \\
\hline $\operatorname{ALB}(g / l) ;$ mean $\pm \mathrm{SE}$ & $26.5 \pm 1.1$ & $28.9 \pm 0.8$ & $0.128^{\mathrm{b}}$ \\
\hline TBIL $(\mu \mathrm{mol} / \mathrm{l})$ & $21.1(5.7-356.3)$ & $18.0(6.7-500.5)$ & $0.753^{\mathrm{a}}$ \\
\hline IBIL $(\mu \mathrm{mol} / \mathrm{l})$ & $8.5(2.5-106.5)$ & $7.6(0.7-108.0)$ & $0.948^{\mathrm{a}}$ \\
\hline DBIL $(\mu \mathrm{mol} / 1)$ & $12.3(2.3-294.2)$ & $11.4(3.1-451.5)$ & $0.867^{\mathrm{a}}$ \\
\hline \multicolumn{4}{|l|}{ Coagulation function } \\
\hline FIB $(g / l)$ & $1.9(0.3-4.8)$ & $1.1(0.5-3.9)$ & $0.093^{\mathrm{a}}$ \\
\hline LDH (U/l) & $942.5(227.0-2597.0)$ & $854.0(131.0-14851.0)$ & $0.838^{\mathrm{a}}$ \\
\hline$\beta 2-\mathrm{MG}(\mathrm{mg} / \mathrm{l}) ;$ mean $\pm \mathrm{SE}$ & $7.5 \pm 1.0$ & $6.6 \pm 0.6$ & $0.467^{\mathrm{b}}$ \\
\hline $\mathrm{TG}(\mathrm{mmol} / \mathrm{l})$ & $3.7(0.9-11.7)$ & $2.6(0.8-8.2)$ & $0.012^{\mathrm{a}}$ \\
\hline Ferritin $(\mu \mathrm{g} / \mathrm{l})$ & $1335.7(316.0-2129.0)$ & $2000.0(760.9-11816.0)$ & $0.014^{\mathrm{a}}$ \\
\hline \multicolumn{4}{|l|}{ BM hemophagocytosis } \\
\hline Yes & 10 & 29 & $1.000^{\mathrm{c}}$ \\
\hline No & 4 & 14 & \\
\hline \multicolumn{4}{|l|}{ EBV DNA copies } \\
\hline$>10^{2}$ & 3 & 33 & $<0.001^{\mathrm{c}}$ \\
\hline$<10^{2}$ & 11 & 10 & \\
\hline
\end{tabular}

LAHS, lymphoma associated hemophagocytic syndrome; SE, standard error; ANC, absolute neutrophil count; Hb, hemoglobin; PLT, platelets; ALT, alanine aminotransferase; AST, aspartate aminotransferase; ALB, albumin; TBIL, total bilirubin; IBIL, indirect bilirubin; DBIL, direct bilirubin; FIB, fibrinogen; LDH, lactate dehydrogenase; $\beta 2-\mathrm{MG}, \beta 2$-microglobulin; TG, triglyceride; BM, bone marrow; EBV, Epstein-Barr virus. ${ }^{\mathrm{a} P}$-value for Mann Whitney U test (median), ${ }^{\mathrm{b}} \mathrm{P}$-value for independent-samples Student's t-test, ${ }^{\mathrm{c} P}$-value for Pearson's $\chi^{2}$ test.

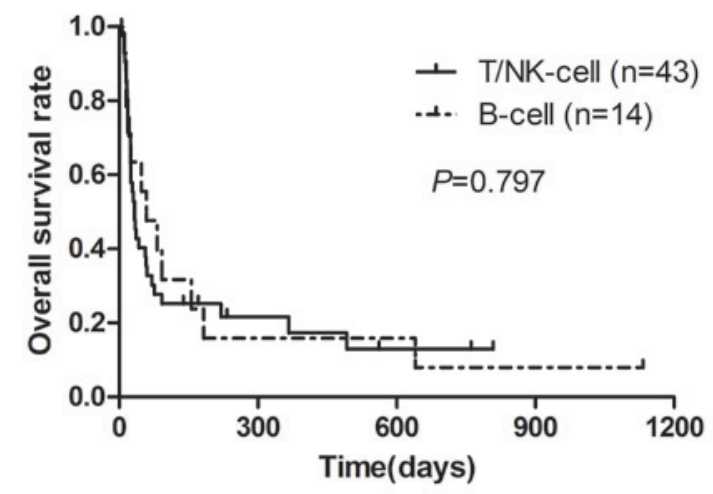

Figure 1. Kaplan-Meier survival analysis of patients with B-cell and T/NK-cell LAHS. The median survival time of B-cell LAHS was 55 days, $0.5,1$ and 2-year OS rates were 16.0, 16.0 and $8.0 \%$, respectively. The median survival time of T/NK-cell LAHS was 40 days, and 0.5, 1 and 2-year OS rates were $26.0,17.0$ and $13.0 \%$, respectively. NK, natural killer; LAHS, lymphoma associated hemophagocytic syndrome; OS, overall survival.

cytokines $(24,25)$. The elevated levels of cytokines secreted by EBV-infected cells cause a series of clinical manifestations (25); however, Ohno et al (24) demonstrated that EBV involvement was not detected in patients with B-cell LAHS, which indicated that EBV infection was not involved in the onset of B-cell LAHS. Instead, numerous reactive $\mathrm{CD} 3+\mathrm{T}$ cells were detected in the bone marrow of all patients with B-cell LAHS, and these reactive T cells were functionally activated, thus indicating that they may be responsible for cytokine production in B-cell LAHS (24).

In the present study, the OS of patients with LAHS was poor. The median survival time was 43 days. Previous studies also reported an inferior OS of patients with LAHS. Barba et al (26) demonstrated that lymphoma was one of the factors associated with increased mortality in patients with HPS. Tong et al (19) conducted a study of 28 patients with aggressive T-cell LAHS and indicated that the median survival time of the patients was 40 days. However, Yu et al (18) reviewed 30 patients with LAHS and reported that the median survival time was 231 days. They indicated that the improved survival may be due to rituximab treatment and HSCT in patients with B-cell LAHS and T-cell LAHS, respectively.

In the present study, although patients with B-cell LAHS exhibited a longer survival time compared with patients with T/NK-cell LAHS, this difference was not statistically significant $(\mathrm{P}=0.797)$. These results were confirmed by $\mathrm{Yu}$ et al (18). However, a number of studies indicated that B-cell lymphoma was associated with a better prognosis compared with T/NK-cell lymphoma $(9,27)$. The potential reasons for the 


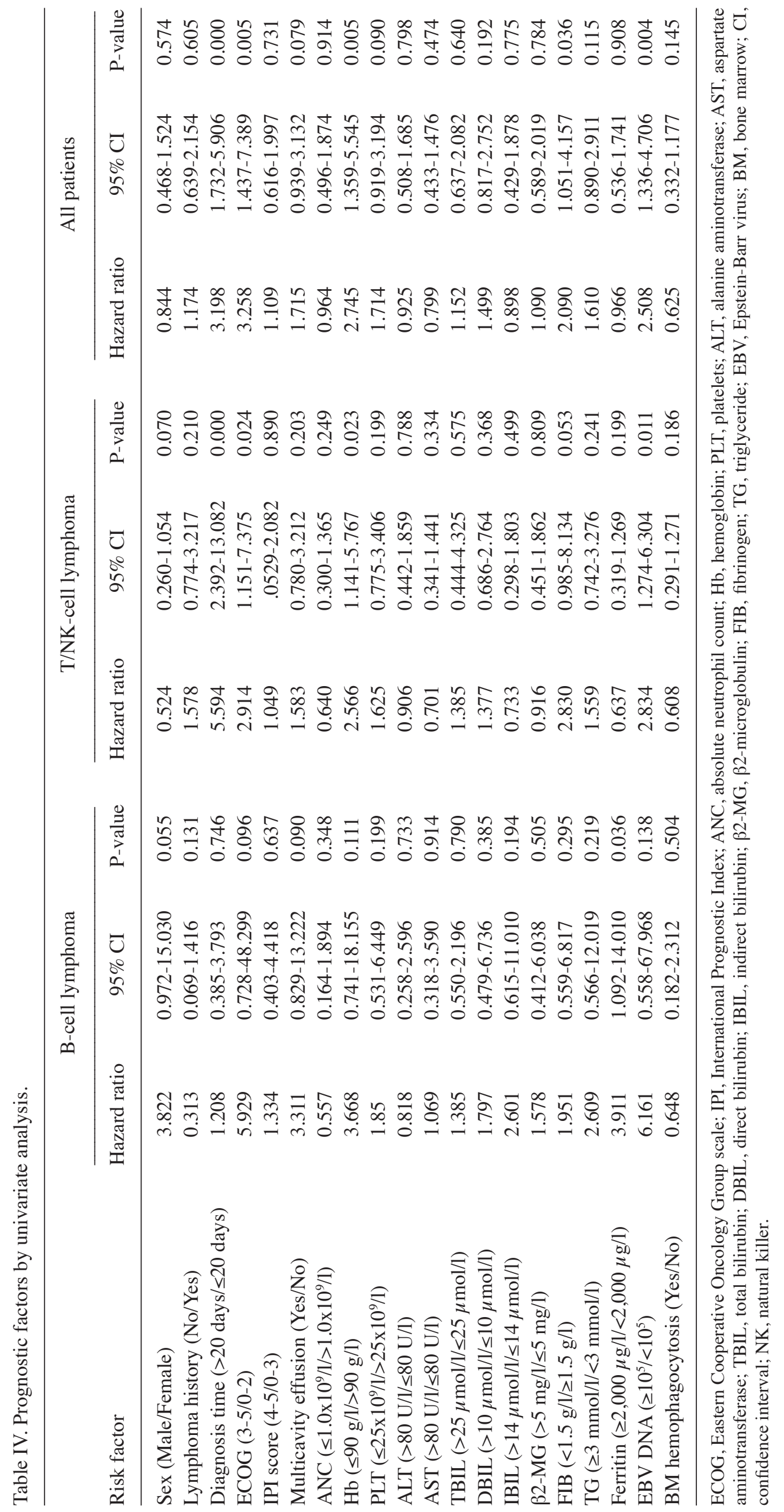


Table V. Prognostic factors by multivariate analysis.

T/NK-cell lymphoma

All patients

\begin{tabular}{|c|c|c|c|c|c|c|}
\hline \multirow[b]{2}{*}{ Risk Factor } & & \\
\hline & Hazard ratio & $95 \% \mathrm{CI}$ & P-value & Hazard ratio & $95 \% \mathrm{CI}$ & P-value \\
\hline Diagnosis time ( $>20$ days/ $\leq 20$ days) & 3.901 & $1.586-9.597$ & 0.003 & 2.182 & $1.123-4.230$ & 0.021 \\
\hline ECOG $(3-5 / 0-2)$ & 2.318 & $0.867-6.541$ & 0.092 & 2.814 & $1.164-6.803$ & 0.022 \\
\hline $\mathrm{Hb}(\leq 90 \mathrm{~g} / \mathrm{l} />90 \mathrm{~g} / \mathrm{l})$ & 1.826 & $0.761-4.382$ & 0.177 & 1.950 & $0.915-4.157$ & 0.084 \\
\hline $\operatorname{FIB}(<1.5 \mathrm{~g} / \mathrm{l} / \geq 1.5 \mathrm{~g} / \mathrm{l})$ & 2.747 & $0.902-8.369$ & 0.075 & 1.448 & $0.700-2.994$ & 0.318 \\
\hline $\operatorname{EBV}$ DNA $\left(\geq 10^{5} /<10^{5}\right)$ & 1.525 & $0.619-3.756$ & 0.359 & 1.834 & $0.947-3.551$ & 0.072 \\
\hline
\end{tabular}

ECOG, Eastern Cooperative Oncology Group scale; Hb, hemoglobin; FIB, fibrinogen; EBV, Epstein-Barr virus; NK, natural killer; CI, confidence interval.
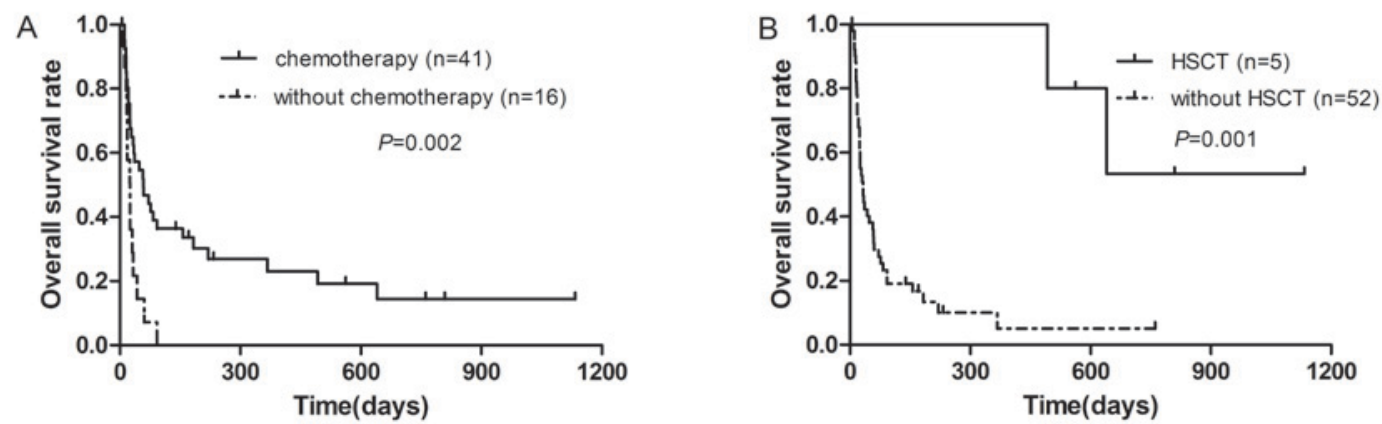

Figure 2. (A) Kaplan-Meier survival analysis of patients treated based on HLH-2004 protocol and chemotherapy vs. patients not treated with chemotherapy (median survival time, 55 vs. 25 days). (B) Patients treated with HSCT vs. patients not treated with HSCT (median survival time, 1,110 vs. 36 days). HSCT, hematopoietic stem cell transplantation.

inconsistencies between the results of these previous studies and the present study was that there were five patients with B-cell LAHS who only received CSA or dexamethasone in the present study.

The median diagnosis time in the present study was 22 days. Univariate and multivariate analysis identified that a long diagnosis time was a poor prognostic factor for patients with LAHS. Numerous factors may influence the diagnosis. For patients with lymphoma suspected of having HPS, misdiagnosis often occurs as fever and pancytopenia may also be caused by severe infection or myelosuppression following chemotherapy. For patients without lymphoma, once the diagnosis of HPS was established, the underlying diseases were difficult to identify, due to a number of patients being too weak to receive biopsies.

Numerous attempts have been made for an early diagnosis of LAHS. It is reported that PET-CT may act as a significant tool to assess patients with LAHS, as it is highly sensitive in detecting neoplasms of the majority of histologic subtypes of lymphoma, and also demonstrates extensive 18-fluorodeoxyglucose (FDG) uptake in tumor tissues (28). It was also reported that the maximum standardized uptake values of patients with malignancy-associated HPS, particularly lymphoma, was statistically higher compared with those with an infection or rheumatosis-associated HPS. Therefore, PET-CT may serve an important role in differential diagnosis of secondary
HPS (29). Furthermore, FDG uptake may reflect the level of cytokine storm to a certain extent and be a prognostic factor for patients with LAHS (30). Tabata et al (10) reviewed 57 LAHS cases and 53 benign disease-associated HPS cases, and indicated that the serum soluble IL-2 receptor (sIL-2R) level and the sIL-2R/ferritin ratio may act as useful markers for distinguishing underlying lymphoma from other causes in patients with HPS. Maruoka et al (31) identified that IFN-inducible protein 10 (IP-10) and monokine induced by IFN- $\gamma$ (MIG) were useful markers for early diagnosis of LAHS. The sensitivity and specificity for the diagnosis were 100 and 95\%, respectively. The serum level of IP-10 and MIG in T or NK/T-cell LAHS were higher compared with those in B-cell LAHS.

HLH-1994 (32) or HLH-2004 protocols are validated treatments for primary HPS. However, the efficacy of these treatment protocols for LAHS is poorly understood. It is generally considered that the most important treatments for LAHS are combined chemotherapy regimens that target malignancy lymphomas $(6,18)$. In the present study, patients who were treated according to the HLH-2004 protocol and with multidrug chemotherapy exhibited improved outcomes compared with those who did not receive chemotherapy, which demonstrates that it is equally important to treat primary diseases as well as treating HPS. Furthermore, the survival time of three patients with B-cell LAHS who received regimens containing rituximab was significantly 

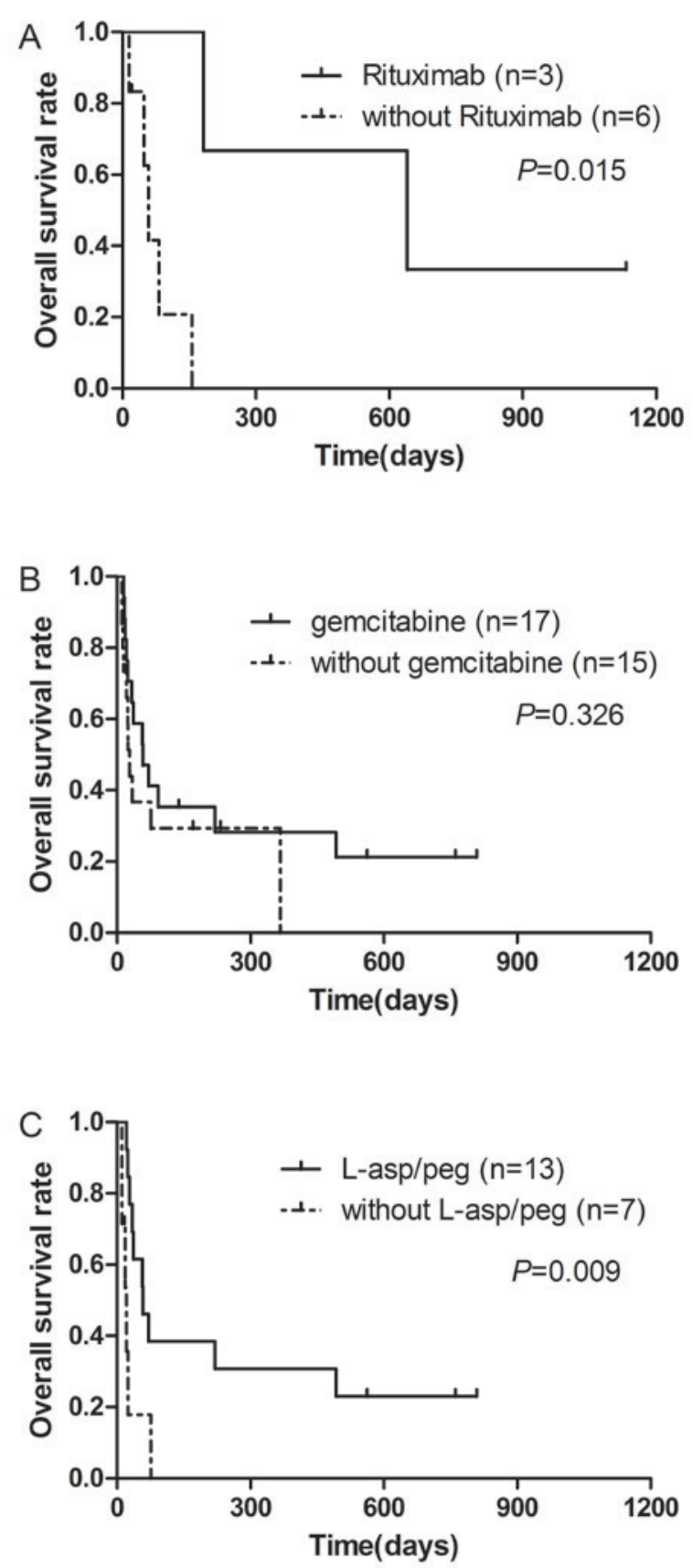

Figure 3. (A) Kaplan-Meier survival analysis of patients with B-cell LAHS treated with chemotherapy plus rituximab vs. patients not treated with rituximab (median survival time, 645 vs. 53 days). (B) Patients with T/NK-cell LAHS treated with gemcitabine-based chemotherapy vs. chemotherapy without gemcitabine (median survival time, 56 vs. 27 days). (C) Patients with NK/T-cell LAHS treated with chemotherapy containing L-asp/peg vs. chemotherapy without L-asp/peg (median survival time: 56 vs. 20 days). LAHS, lymphoma associated hemophagocytic syndrome; L-asp/peg, L-asparaginase/pegaspargase; NK, natural killer.

longer compared with those who did not receive rituximab. This survival benefit may be due to introducing rituximab. To date, gemcitabine-based combination chemotherapy has been demonstrated to be highly successful in improving the treatment outcome of T/NK-cell lymphoma (33-35). However, in the present study patients with $\mathrm{T} / \mathrm{NK}$-cell LAHS who were treated with gemcitabine did not exhibit survival advantage. L-asp/peg-based regimens were analyzed in the ENKL group and led to an improved prognosis. L-asp/peg-containing regimens have been indicated to be highly effective for patients with NK/T-cell lymphoma (35). The prior studies also demonstrated that the significant efficacy and safety profile of the peg-based regimen in the treatment of newly diagnosed and relapsed/refractory ENKL (35-37). The anticancer effect of L-asp is not affected by multidrug resistance gene due to its unique mechanism (37). Since ENKL cells cannot synthesize asparagine themselves, tumor cell proliferation is suppressed under the effect of hydrolyzing asparagine by L-asp (38).

It was reported that patients with primary HPS may achieve long-term survival following a treatment regime of immunochemotherapy combined with HSCT (11). A large prospective study of 249 patients with familial, refractory or recurrent HPS indicated that the 5-year survival rate of 124 patients who underwent HSCT was $66 \pm 8 \%$ (39). A study comparing reduced intensity conditioning (RIC) regimens with myeloablative conditioning (MAC) regimens demonstrated that the overall 3-year survival following HSCT was $43 \%$ for patients with MAC and 92\% for patients with RIC (40). However, HSCT has rarely been reported as a treatment of LAHS, and the efficacy remains unknown. It was reported that a number of patients with LAHS achieved CR and obtained long-term survival from allogeneic or autologous $\operatorname{HSCT}(8,18,41,42)$. The present study indicated that HSCT may improve the outcome of patients with LAHS. However, further research is required to investigate the role of HSCT in LAHS treatment.

The present study has several limitations. The study was retrospectively conducted from a single center, and the number of patients involved was relatively small. Additionally, NK cell activity and soluble CD25 levels were not analyzed.

In conclusion, LAHS is relatively common but has the worst prognosis of secondary HPS types, and it poses a challenge to clinicians (43). The results of the present study demonstrated that the survival time did not differ between patients with B-cell and T/NK-cell LAHS. Early diagnosis and immunochemotherapy plus HSCT may lead to better outcomes. Treatment of the underlying lymphoma in patients with LAHS ought to be treated at the same time as the implementation of countermeasures for the suppression of the extreme inflammation triggered by HPS. The outcome of patients with B-cell LAHS may be significantly improved following treatment with rituximab. L-asp/peg-containing regimens are promising treatments if NK/T-cell lymphomas are recognized as an underlying disease. Prospective multicenter studies with larger sample sizes are required for an optimal treatment for LAHS.

\section{Acknowledgements}

The authors would like to thank Yingjun Wang and Li Tian from Lymphoma Diagnosis and Treatment Centre of Henan Province for providing clinical data.

\section{Funding}

The present study was supported by the National Natural Science Foundation of China (grant no. 81570203). 


\section{Availability of data and materials}

All data analyzed during this study are included in this published article.

\section{Authors' contributions}

YC, GS and MZ designed the study, interpreted the results and wrote the manuscript. MC, XF, LH and LZ performed the data analysis and statistical analysis. LL, XL, ZS, JW, XZ, ZL, $\mathrm{FN}$ and JY performed literature research and the clinical data acquisition.

\section{Ethics approval and consent to participate}

This study was approved by the ethics committee of the First Affiliated Hospital of Zhengzhou University. Written informed consent for the collection of medical information was obtained from all patients.

\section{Consent for publication}

Informed consent for the collection and publication of medical information was obtained from all patients.

\section{Competing interests}

The authors declare that they have no competing interests.

\section{References}

1. Risdall RJ, McKenna RW, Nesbit ME, Krivit W, Balfour HJ, Simmons RL and Brunning RD: Virus-associated hemophagocytic syndrome: A benign histiocytic proliferation distinct from malignant histiocytosis. Cancer 3: 993-1002, 1979.

2. Szyper-Kravitz M: The hemophagocytic syndrome/macrophage activation syndrome: A final common pathway of a cytokine storm. Isr Med Assoc J 10: 633-634, 2009.

3. Janka GE and Lehmberg K: Hemophagocytic lymphohistiocytosis: Pathogenesis and treatment. Hematology Am Soc Hematol Educ Program 2013: 605-611, 2013.

4. Rouphael NG, Talati NJ, Vaughan C, Cunningham K, Moreira R and Gould C: Infections associated with haemophagocytic syndrome. Lancet Infect Dis 12: 814-822, 2007.

5. Janka GE and Lehmberg K: Hemophagocytic syndromes-an update. Blood Rev 4: 135-142, 2014.

6. Han L, Li L, Wu J, Li X, Zhang L, Wang X, Fu X, Ma W, Sun Z, Zhang $\mathrm{X}$, et al: Clinical features and treatment of natural killer/T cell lymphoma associated with hemophagocytic syndrome: Comparison with other T cell lymphoma associated with hemophagocytic syndrome. Leuk Lymphoma 9: 2048-2055, 2014.

7. Parikh SA, Kapoor P, Letendre L, Kumar S and Wolanskyj AP Prognostic factors and outcomes of adults with hemophagocytic lymphohistiocytosis. Mayo Clin Proc 89: 484-492, 2014.

8. Han AR, Lee HR, Park BB, Hwang IG, Park S, Lee SC, Kim K Lim HY, Ko YH, Kim SH and Kim WS: Lymphoma-associated hemophagocytic syndrome: Clinical features and treatment outcome. Ann Hematol 86: 493-498, 2007.

9. Sano H, Kobayashi R, Tanaka J, Hashino S, Ota S, Torimoto Y, Kakinoki Y, Yamamoto S, Kurosawa M, Hatakeyama N, et al: Risk factor analysis of non-Hodgkin lymphoma-associated haemophagocytic syndromes: A multicentre study. Br J Haematol 165: 786-792, 2014.

10. Tabata $\mathrm{C}$ and Tabata $\mathrm{R}$ : Possible prediction of underlying lymphoma by high sIL-2R/ferritin ratio in hemophagocytic syndrome. Ann Hematol 91: 63-71, 2012.

11. Seo JJ: Hematopoietic cell transplantation for hemophagocytic lymphohistiocytosis: Recent advances and controversies. Blood Res 50: 131-139, 2015.
12. Sabattini E, Bacci F, Sagramoso C and Pileri SA: WHO classification of tumours of haematopoietic and lymphoid tissues in 2008: An overview. Pathologica 102: 83-87, 2010.

13. Henter JI, Horne A, Arico M, Egeler RM, Filipovich AH, Imashuku S, Ladisch S, McClain K, Webb D, Winiarski J and Janka G: HLH-2004: Diagnostic and therapeutic guidelines for hemophagocytic lymphohistiocytosis. Pediatr Blood Cancer 48: 124-131, 2007.

14. Olweny CL: Cotswolds modification of the Ann Arbor staging system for Hodgkin's disease. J Clin Oncol 9: 1598, 1990.

15. Oken MM, Creech RH, Tormey DC, Horton J, Davis TE, McFadden ET and Carbone PP: Toxicity and response criteria of the Eastern cooperative oncology group. Am J Clin Oncol 5: 649-655, 1982.

16. Cheson BD, Pfistner B, Juweid ME, Gascoyne RD, Specht L, Horning SJ, Coiffier B, Fisher RI, Hagenbeek A, Zucca E, et al: Revised response criteria for malignant lymphoma. J Clin Oncol 25: 579-586, 2007.

17. Takahashi N, Chubachi A, Miura I, Nakamura S and Miura AB: Lymphoma-associated hemophagocytic syndrome in Japan. Rinsho Ketsueki 40: 542-549, 1999 (In Japanese).

18. Yu JT, Wang CY, Yang Y, Wang RC, Chang KH, Hwang WL and Teng CL: Lymphoma-associated hemophagocytic lymphohistiocytosis: Experience in adults from a single institution. Ann Hematol 11: 1529-1536, 2013

19. Tong H, Ren Y, Liu H, Xiao F, Mai W, Meng H, Qian W, Huang J, Mao L, Tong Y, et al: Clinical characteristics of T-cell lymphoma associated with hemophagocytic syndrome: Comparison of T-cell lymphoma with and without hemophagocytic syndrome. Leuk Lymphoma 49: 81-87, 2008.

20. Allen CE, Yu X, Kozinetz CA and McClain KL: Highly elevated ferritin levels and the diagnosis of hemophagocytic lymphohistiocytosis. Pediatr Blood Cancer 50: 1227-1235, 2008.

21. Chen YP, Jones D, Chen TY and Chang KC: Epstein-Barr virus present in $\mathrm{T}$ cells or B cells shows differential effects on hemophagocytic symptoms associated with outcome in T-cell lymphomas. Leuk Lymphoma 55: 2038-2047, 2014.

22. Kwong YL, Pang AW, Leung AY, Chim CS and Tse E: Quantification of circulating Epstein-Barr virus DNA in NK/T-cell lymphoma treated with the SMILE protocol: Diagnostic and prognostic significance. Leukemia 28: 865-870, 2014.

23. Suzuki R, Yamaguchi M, Izutsu K, Yamamoto G, Takada K, Harabuchi Y, Isobe Y, Gomyo H, Koike T, Okamoto M, et al: Prospective measurement of Epstein-Barr virus-DNA in plasma and peripheral blood mononuclear cells of extranodal NK/T-cell lymphoma, nasal type. Blood 118: 6018-6022, 2011.

24. Ohno T, Ueda Y, Nagai K, Takahashi T, Konaka Y, Takamatsu T, Suzuki T, Sasada M and Uchiyama T; Kyoto University Hematology/Oncology Study Group: The serum cytokine profiles of lymphoma-associated hemophagocytic syndrome: A comparative analysis of B-cell and T-cell/natural killer cell lymphomas. Int J Hematol 77: 286-294, 2003.

25. Chuang HC, Lay JD, Hsieh WC and Su IJ: Pathogenesis and mechanism of disease progression from hemophagocytic lymphohistiocytosis to Epstein-Barr virus-associated T-cell lymphoma: Nuclear factor-kappa B pathway as a potential therapeutic target. Cancer Sci 98: 1281-1287, 2007.

26. Barba T, Maucort-Boulch D, Iwaz J, Bohé J, Ninet J, Hot A, Lega JC, Guérin C, Argaud L, Broussolle C, et al: Hemophagocytic Lymphohistiocytosis in intensive care unit: A 71-case strobe-compliant retrospective study. Medicine (Baltimore) 94: e2318, 2015.

27. Cattaneo C, Oberti M, Skert C, Passi A, Farina M, Re A, Tozzi P, Borlenghi E and Rossi G: Adult onset hemophagocytic lymphohistiocytosis prognosis is affected by underlying disease and coexisting viral infection: Analysis of a single institution series of 35 patients. Hematol Oncol 35: 828-834, 2017.

28. Yiu CR, Kao YH, Phipps C and Tan D: Positron emission tomography findings in patients with lymphoma-associated haemophagocytic syndrome. Singapore Med J 7: e156-e159, 2011.

29. Zhang LJ, Xu J, Liu P, Ding CY, Li JY, Qiu HX and Zhang SJ: The significance of 18F-FDG PET/CT in secondary hemophagocytic lymphohistiocytosis. J Hematol Oncol 5: 40, 2012.

30. Yang YQ, Ding CY, Xu J, Fan L, Wang L, Tian T, Li TN, Li JY and $\mathrm{Xu} \mathrm{W}$ : Exploring the role of bone marrow increased FDG uptake on PET/CT in patients with lymphoma-associated hemophagocytic lymphohistiocytosis: A reflection of bone marrow involvement or cytokine storm? Leuk Lymphoma: Jun 19, 1-8, 2015 (Epub ahead of print). 
31. Maruoka H, Inoue D, Takiuchi Y, Nagano S, Arima H, Tabata S, Matsushita A, Ishikawa T, Oita T and Takahashi T: IP-10/CXCL10 and MIG/CXCL9 as novel markers for the diagnosis of lymphoma-associated hemophagocytic syndrome. Ann Hematol 3: 393-401, 2014.

32. Henter JI, Arico M, Egeler RM, Elinder G, Favara BE, Filipovich AH, Gadner H, Imashuku S, Janka-Schaub G, Komp D, et al: HLH-94: A treatment protocol for hemophagocytic lymphohistiocytosis. HLH study group of the histiocyte society. Med Pediatr Oncol 28: 342-347, 1997.

33. Park BB, Kim WS, Suh C, Shin DY, Kim JA, Kim HG and Lee WS: Salvage chemotherapy of gemcitabine, dexamethasone, and cisplatin (GDP) for patients with relapsed or refractory peripheral T-cell lymphomas: A consortium for improving survival of lymphoma (CISL) trial. Ann Hematol 94: 1845-1851, 2015.

34. Pellegrini C, Dodero A, Chiappella A, Monaco F, Degl'Innocenti D, Salvi F, Vitolo U, Argnani L, Corradini P and Zinzani PL; Italian Lymphoma Foundation (Fondazione Italiana Linfomi Onlus, FIL): A phase II study on the role of gemcitabine plus romidepsin (GEMRO regimen) in the treatment of relapsed/refractory peripheral T-cell lymphoma patients. J Hematol Oncol 9: 38, 2016

35. Li X, Cui Y, Sun Z, Zhang L, Li L, Wang X, Wu J, Fu X, Ma W, Zhang X, et al: DDGP versus SMILE in newly diagnosed advanced natural Killer/T cell lymphoma: A randomized controlled, multicenter, Open-label study in China. Clin Cancer Res 22: 5223-5228, 2016.

36. Li L, Zhang C, Zhang L, Li X, Wu JJ, Sun ZC, Fu XR, Wang XH, Chang Y, Wang R, et al: Efficacy of a pegaspargase-based regimen in the treatment of newly-diagnosed extranodal natural killer/T-cell lymphoma. Neoplasma 61: 225-232, 2014.

37. Zhou Z, Li X, Chen C, Li X, Zhang L, Li L, Wang X, Ma W, $\mathrm{Fu} \mathrm{X}, \mathrm{Wu} \mathrm{J}$, et al: Effectiveness of gemcitabine, pegaspargase, cisplatin, and dexamethasone (DDGP) combination chemotherapy in the treatment of relapsed/refractory extranodal NK/T cell lymphoma: A retrospective study of 17 patients. Ann Hematol 93: 1889-1894, 2014.
38. Kwong YL, Kim WS, Lim ST, Kim SJ, Tang T, Tse E, Leung AY and Chim CS: SMILE for natural killer/T-cell lymphoma: Analysis of safety and efficacy from the Asia lymphoma study group. Blood 120: 2973-2980, 2012

39. Trottestam H, Horne A, Arico M, Egeler RM, Filipovich AH, Gadner H, Imashuku S, Ladisch S, Webb D, Janka G, et al: Chemoimmunotherapy for hemophagocytic lymphohistiocytosis: Long-term results of the HLH-94 treatment protocol. Blood 118: 4577-4584, 2011

40. Marsh RA, Vaughn G, Kim MO, Li D, Jodele S, Joshi S, Mehta PA, Davies SM, Jordan MB, Bleesing JJ and Filipovich AH: Reduced-intensity conditioning significantly improves survival of patients with hemophagocytic lymphohistiocytosis undergoing allogeneic hematopoietic cell transplantation. Blood 116: 5824-5831, 2010

41. Machaczka M, Nahi H, Karbach H, Klimkowska $M$ and Hagglund H: Successful treatment of recurrent malignancy-associated hemophagocytic lymphohistiocytosis with a modified HLH-94 immunochemotherapy and allogeneic stem cell transplantation. Med Oncol 29: 1231-1236, 2012.

42. Inoue D, Nagai Y, Takiuchi Y, Nagano S, Arima H, Kimura T, Shimoji S, Mori M, Togami K, Tabata S, et al: Successful treatment of extranodal natural killer/T-cell lymphoma, nasal type, complicated by severe hemophagocytic syndrome, with dexamethasone, methotrexate, ifosfamide, L-asparaginase, and etoposide chemotherapy followed by autologous stem cell transplant. Leuk Lymphoma 51: 720-723, 2010.

43. George MR: Hemophagocytic lymphohistiocytosis: Review of etiologies and management. J Blood Med 5: 69-86, 2014. 